\title{
Ego-Resiliency, Parenting Style, and Peer Attachment as Predictors of South Korean Middle School Students' School Adjustment
}

\author{
Byeolbee $\mathrm{Um}^{1}$ \\ ${ }^{1}$ Department of Elementary Counseling Education, Seoul National University of Education, Seoul, South Korea \\ Correspondence: Byeolbee Um, Department of Elementary Counseling Education, Seoul National University of \\ Education, Seoul, South Korea.
}

Received: May 21, 2018

Accepted: June 8, $2018 \quad$ Available online: June 22, 2018

doi:10.11114/ijsss.v6i7.3290

URL: https://doi.org/10.11114/ijsss.v6i7.3290

\begin{abstract}
The purpose of this study is to identify the relative contribution of South Korean middle school students' ego-resiliency, parenting style, and peer attachment in predicting their school adjustment. For this purpose, only South Korean $7^{\text {th }}$ graders' cross-sectional data of 2016 were extracted from the Korean Children and Youth Panel Survey (KCYPS) and then, using SPSS version 24.0, analyzed by Pearson's correlation coefficient and hierarchical multiple regression. The results were as follows. First, there were significant positive correlations between ego-resiliency, parenting style, peer attachment, and school adjustment variables, except for some relationships within and between sub-variables of them. Second, ego-resiliency, parenting style, and peer attachment made a significant prediction for school adjustment and its sub-variables in order of ego-resiliency, parenting style, and peer attachment. Subsequently, the present research discussed these findings' implications with the previous works.
\end{abstract}

Keywords: South Korean middle school students, ego-resiliency, parenting style, peer attachment, school adjustment, Korean Children and Youth Panel Survey (KCYPS)

\section{Introduction}

School adjustment is a critical developmental task for South Korean adolescents who spend most of their time at school (Keum, Son, Chae, \& Kang, 2013; Cho, 2013). Regardless of the inside and outside of the country, to date, many researchers have continually studied school adjustment. The reason for that lies in that the way adolescents make the academic and social adjustment to middle school has a constant influence upon their cognitive, emotional, and social development later (Elliot \& Feldman, 1990; Chang, Song, \& Cho, 2011; Han \& Bang, 2017). There currently is almost no universal definition of adolescent school adjustment. However, it primarily refers to the active process which adolescents try to strike a balance between individuals and school environment, modifying themselves or environments with positive attitudes toward school to satisfy their needs (Bierman, 1994; Hall \& Diperna, 2017). As this definition implies a way of problem-solving relating to school life, adjustment to school also is crucial to achievement, interpersonal relationship, and mental health of people later (Hall \& Diperna, 2017; Ryan \& Shim, 2008; Xia, Wang, Li, Wilson, Bush, \& Peterson, 2015).

Recently, nevertheless, a growing number of adolescents are facing with school adjustment problems in South Korea (Joo \& Kwon, 2017; Keum et al., 2013; Ministry of Education, 2016; Ministry of Gender and Family, 2016; Shin \& Son, 2016). By empirical research, Cho (2012) found that one in two South Korean $7^{\text {th }}$ graders were close to school maladjustment and 7\% of them already had severe maladjustment. Keogh (2003) pointed out that adolescents with school adjustment problems felt anxiety, anger, depression, or excessive stress or show withdrawn, disruptive, aggressive, or non-compliant behavior. Hence, they become difficult with learning subjects and maintaining an appropriate friendship or teacher-student relationship (Hall \& Diperna, 2017; Han \& Bang, 2017; Ryan \& Shim, 2008). Such students, in turn, may be involved in school violence problem, having a suicidal thought, or dropping out of school (Han \& Bang, 2017; Keogh, 2003; National Youth Policy Institute, 2013). Specifically, several surveys showed that 6.4\% of students experienced bullying at school (The Foundation for Prevention Youth Violence, 2016) and that among $6,680,000$ indicating a total number of South Korean school-aged youth, about 392,000 became youth out of school in 2014 (Ministry of Gender and Family, 2016). Even National Youth Policy Institute (2013) found that 36.9\% of middle school students thought about killing themselves. Since these outcomes cast a gloomy and dark shadow over students' 
happiness as well as the future of the country, it is necessary to delve into the causes of school adjustment problems before coming up with specific measures for them.

These adjustment problems of middle school students can mostly blame on their rapid physical and emotional changes, the undue achievement pressure from parents or teachers on children, and the uncertain and transitional period from elementary school to high school (Elliot \& Feldman, 1990; Hall \& Diperna, 2017; Keum et. al., 2013; Laible, Carlo, \& Raffaelli, 2000; Sasikala \& Cecil, 2016). In recent, even frequent changes of entrance examination system and a growing sense of helplessness by the spoon class argument in South Korea are rapidly emerging as factors which make school adjustment difficult (Korea Joongang daily, 2017. 8. 19; SBS, 2018. 4. 2). To reduce these factors, when we approach adolescents' school adjustment, there is a need to view in the big picture which has these factors categorized as individual, family, peer, and other environmental dimensions (Cho, 2013; Demanet \& Van Houtte, 2012). In this way, Bronfenbrenner's theory (1979) can be helpful to approach school adjustment. He suggested that the complex layers of the environment related to a child's development and consisted of five systems according to the proximity from a child (Bronfenbrenner, 1979). Considering Bronfenbrenner's theory, though it may be useful to regard even exosystem, macrosystem, and chronosystem outside as the factors of school adjustment, we focused on microsystems and mesosystem closer to a child. Of five systems, mesosystem means the interactions among microsystems. Microsystem, which has a direct influence on a child, is composed of family, peer, and school including a child himself. Drawing on this discussion, to focus on factors directly affecting school adjustment and set out a balanced approach to it, the current study selected one variable in individual, family, and peer dimensions respectively (Al-Hendawi, 2013; Keogh, 2003; Oldfield, Neil, \& Hebron, 2016; Sarkar \& Ray, 2017; Williams, Ciarrochi, \& Heaven, 2012).

First, in individual dimension, many researchers have suggested various variables such as temperament, self-esteem, ego-resiliency, emotion, and social skill as predictors of adjustment to middle school (Al-Hendawi, 2013; Hall \& Diperna, 2017; Keogh, 2003; Martin, 1994; Mestre, Guil, Lopes, Salovey, \& Gil-Olarte, 2006). Particularly, ego-resilience whose concept itself implies adaptability is rapidly emerging as predictors of school adjustment in lots of investigations (Block \& Block, 1980; Kim \& Jang, 2015; Liew, Cao, Hughes, \& Deutz, 2018). Compared to resiliency implying a generalized and characterological quality of an individual, ego-resilience is a personality trait that reflects an individual's adaptability to novel or stressful situation to preserve or improve system equilibration (Al-Hendawi, 2013; Block \& Block, 1980; Block \& Kremen, 1996). In other words, as ego-resiliency means the dynamic ability to respond flexibly to situational demands such as acute stress, conflicts, or uncertainty, it is conceptually related to the constructs including competence, social intelligence, coping behavior (Block \& Kremen, 1996).

Accordingly, students who have a higher level of ego-resiliency are better able to adjust themselves to changing or stressful situations, shift behaviors as needed, and implement problem-solving strategies flexibly (Block \& Block, 1980). Besides, for more ego-resilient individuals, there is a strong possibility that they continually do well in the transitional period from adolescence to adulthood (Arnett, 2000; Laursen \& Collins, 2012). Consistent with these earlier studies, Shin and Son (2016) found that ego-resiliency was a significant predictor of school adjustment and its sub-variables (learning activity, school rule, friendship, and teacher-student relationship). Most other findings also showed that ego-resiliency significantly predicted school adjustment or its sub-variables regardless of ages, socioeconomic status, and races (Han \& Bang, 2017; Liew et al., 2018). To our knowledge, however, there is little to confirm the relative predictive power of ego-resiliency among individual, family, and peer dimension in an attempt to predict school adjustment in balance.

Researchers have regarded, in the family being safe havens for adolescents, family structure, family strength, parenting style, and socioeconomic status as predictors of adolescents' school adjustment (Bardack, Herbers, \& Obradović, 2017; Baytemir, 2016; Cho, 2013; Darling \& Steinberg, 1993; Chang et al., 2011; Keum et. al., 2013; Sasikala \& Cecil, 2016; Sarkar \& Ray, 2017; Stipek, 1997). As has just been described, though studies have identified many variables as components of predicting school adjustment, parenting style has especially received many researchers' attention (Huang \& Gove, 2016; Inam, Nomaan, \& Abiodullah, 2016; Lee \& Kang, 2017; Odong, Aloka, \& Raburu, 2016; Pinquart, 2015; Spera, 2005). Parenting style is the generic term for how much parents support or are strict on their children's attitudes or behaviors (Coleman, Ganong, \& Fine, 2000; Ladd \& Price, 1987).

In the growth process, parenting style influences the quality of parent-child relationship and, in turn, serves as the prototype for a later interpersonal relationship (Bardack, Herbers, \& Obradović, 2017; Yates, Obradović, \& Egeland, 2010). Furthermore, as parenting style is the critical factors for children's academic achievement, it will play a crucial role in school adjustment covering friendship, teacher-student relationship, and learning activity (Lee \& Kang, 2017; Odong et al., 2016; Pinquart, 2015; Shin \& Son, 2016). Reflecting the findings that parenting style predicted psychosocial adjustment in young adulthood, it is likely that parenting style predicts the school rule, friendship, and the teacher-student relationship of school adjustment, too (Betts, Trueman, Chiverton, Stanbridge, \& Stephens, 2013). In practice, Chen, Dong, and Zhou (1997) found that authoritarian parenting style was correlated negatively with peer 
acceptance, social competence, distinguished studentship, and academic achievement whereas the authoritative style was associated positively with social and school adjustment. More specifically, Shin and Son (2016) demonstrated that supervision, affection, and rational explanation positively predicted school adjustment while inconsistency, unreasonable expectation, and excessive interference negatively made school adjustment. Of course, the work also raised the possibility that there may be somewhat different depending on grade levels and sub-variables of school adjustment. To sum it up, parenting style and its sub-variables are expected to predict adolescents' school adjustment significantly (Chen et al., 1997; Huang \& Gove, 2016; Inam et al., 2016; Odong et al., 2016; Pinquart, 2015; Shin \& Sonn, 2016).

Entering into adolescence, since safe havens gradually shift from parents to peers and the power of peer increases, peers play a growingly important role in adolescents' school adjustment (Allen, 2008; Cho, 2013; Chang et al., 2011; Laible et al., 2000; Oldfield et al., 2016; Sasikala \& Cecil, 2016). So far, with regard to peer dimension, lots of studies have presented peer attachment, the interaction with friends, peer acceptance, number of friends as the principal predictors of adolescents' school adjustment (Altermatt, 2011; Baytemir, 2016; Oldfield et al., 2016; Ryan, 2000; Sarkar \& Ray, 2017; Sasikala \& Cecil, 2016). Among them, as peer attachment is the basis of other variables, it appears to be a significant variable for successfully adapting to school (Baytmir, 2016; Chang et al., 2011). Peer attachment referring to the emotional bond with a peer, means the positive peer relationship in which peers share information or attitude, communicate feelings or thoughts, and trust each other (Altermatt, 2011; Armsden \& Greenberg, 1987; Ryan, 2000).

As a lot of investigations have suggested, peer groups serve as a lot of valuable roles throughout adolescence, providing not only safety havens to rely on, receive support and honestly communicate but also a temporary reference point for developing a sense of identity (Oldfield et al., 2016; Sasikala \& Cecil, 2016). Moreover, for adolescents who spend most of the time with peers at school, peer attachment is one of the significant variables for successfully adapting to school in that it contributes to developing social skills, relieving stress, achieving information, and getting support (Lee \& Kang, 2017; Laible et al., 2000; Oldfield et al., 2016; Ryan, 2000; Tomada, Schneider, de Domini, Greenman, \& Fonzi, 2005). Thanks to these contributions of peer attachment, in reality, adolescents with a higher level of peer attachment were more likely to adapt to school (Chang et al., 2011). Subsequently, as a result of analyzing the sub-variables of peer attachment, Chang et al. (2011) also successfully found that communication and trust except for alienation were a significant predictor of adolescents' school adjustment, implying that adolescents with a higher level of communication and trust were better at adapting to school. Building on above discussion, the current work expects that peer attachment and its sub-variable significantly predict school adjustment even though there are somewhat differences depending upon sub-variables of peer attachment and school adjustment (Altermatt, 2011; Armsden \& Greenberg, 1987; Laible et al., 2000; Oldfield et al., 2016; Sasikala \& Cecil, 2016).

As discussed above, it has relatively well established that one or two of ego-resiliency, parenting style, and peer attachment have at least some influence on adolescents' school adjustment at both home and abroad. To the best of our knowledge, however, less is known about study putting these three variables in at the same time and then analyzing their relative contribution to predicting school adjustment. That being so, there is a need for research for examining a relative contribution of ego-resiliency, parenting style, and peer attachment in predicting school adjustment. From this necessity for investigating, we intended to identify the relative contribution of their ego-resiliency, parenting style, and peer attachment in predicting their school adjustment. For this purpose, we suggested research questions as follows:

1) What are the correlations between ego-resiliency, parenting style, peer attachment, and school adjustment respectively?

2) What is the relative predictive power of ego-resiliency, parenting style, and peer attachment on school adjustment?

\section{Method}

\subsection{Participants}

Though Korean Children and Youth Panel Survey (KCYPS) has annually collected data about three groups from 2010 (grade 1, grade 4, and grade 7) to 2016 (grade 7, grade 10, and college freshman), this work extracted only South Korean $7^{\text {th }}$ graders' cross-section data of 2016. In result, the sample of this article consisted of 2001 (1039 male, 962 female) $7^{\text {th }}$ graders, participating in KCYPS in 2016, who were sampled from South Korean middle schools nationwide in proportion to the number of classes by National Youth Policy Institute (NYPI).

\subsection{Instruments}

The KCYPS coded data with a score from 1=strongly agree to 4=strongly disagree at first. As such, for representing that the higher scores, the stronger traits, this study reversely coded all data except for three factors concerning the negative sub-variables of parenting styles (inconsistency, unreasonable expectation, and excessive interference) and one 
factor regarding alienation of peer attachment so that they ranged from 1=strongly disagree through 4=strongly agree. Of course, the present study reversely coded even the negative sub-variables of parenting styles and alienation for calculating total parenting style and peer attachment.

\subsubsection{Ego-Resiliency}

The ego-resiliency scale being a single factor is a 14-item scale on a 4-point Likert scale. The KCYPS revised it from the ego-resiliency scale which Yoo and Sim (2002) translated and revised from that of Block and Kremen (1996). Cronbach's $\alpha$ coefficient of this scale was .89. Examples of items are as follows: "I am generous to my friend," "Although I am suddenly frightened, I get well soon and overcome it," and "My life is full of interesting things every day."

\subsubsection{Parenting Style}

The parenting style scale is a 21 -item scale on a 4-point Likert scale consisting of supervision ( 3 items), affection (4 items), rational explanation (3 items), inconsistency ( 3 items), unreasonable expectation (4 items), and excessive interference (4 items). The KCYPS extracted and revised parenting style scale from Heo's parenting style scale (2000). Cronbach's $\alpha$ coefficient was . 86 for the whole scale and ranged from .70 to .83 for the subscales. The positive items are "My parents know how I spent my time (supervision)," "My parents express that they love me (affection)," and "My parents explain why I should do it rather than following my parents' decisions unconditionally (rational explanation)." In the other hand, the negative items are "My parents treat me as the freak takes them (inconsistency)," "My parents' expectations are always higher than my ability (unreasonable expectation)," and "My parents often don't let me do what I want (excessive interference)."

\subsubsection{Peer Attachment}

The peer attachment scale is a 9-item questionnaire divided into three subscales such as communication (3 items), trust (3 items), and alienation ( 3 items). The KCYPS extracted and revised peer attachment scale from Hwang's peer attachment scale (2010) translated from that of Armsden and Greenberg (1987). Cronbach's $\alpha$ coefficient for the whole scale was .82 , and those for the subscales ranged from .70 to .84 . There are items such as "My friends respect my thoughts when I talk to them (communication)," "I can tell my friends when I want to open my heart (trust)," and "I feel lonely even though I am with my friends (alienation)."

\subsubsection{School Adjustment}

This article used a 20-item scale on a 4-point Likert scale, consisting of four subscales such as learning activity (5 items), school rule (5 items), friendship (5 items), and teacher-student relationship (5 items) to measure the students' school adjustment. The KCYPS modified school adjustment scale from that of Min (1991). As a result of analyzing reliability, Cronbach's $\alpha$ coefficients were .90 for the whole scale and ranged from .67 to .84 for the subscales. Examples of items are as follows: "I know well what I learned in classes (learning activity)," "I always put trash in a trash bin (school rule)," "I get along with my classmates (friendship)," and "I feel comfortable to talk to my teacher (teacher-student relationship)."

\subsection{Data Analysis}

In this work, researchers calculated Cronbach's $\alpha$ coefficient for each instrument and descriptive statistics before performing Pearson correlation and hierarchical multiple regression to solve the research question. For verifying the relative predictive power of $7^{\text {th }}$ graders' ego-resiliency, parenting style, and peer attachment on school adjustment, the current study puts these independent variables in order of an individual, family, and peer dimension. The present research processed data using SPSS 24.0 version and set a significant level of .05.

\section{Results}

\subsection{The Results of Correlation Analysis}

Before entering into multiple regression analysis, descriptive statistics for all variables in this article and Pearson's correlation analysis between them are presented in Table 1 .

At the bottom of Table 1, there are the means, standard deviations, skewness, and kurtosis of all variables. The skewness and kurtosis of each variable were examined to identify the normality assumption. The skewness of variables ranged from -.697 to .711 and the range of their kurtosis was from -589 to .535 . Since the skewness and kurtosis of all variables and their sub-variables have absolute values less than three and seven respectively, it met the normality assumption.

Subsequently, all the correlations between ego-resiliency, parenting style, peer attachment, and school adjustment are as follows (Table 1). First, ego-resiliency had positive correlations with parenting style, peer attachment, and school 
adjustment and their sub-variables except for inconsistency, excessive interference, and alienation. Concretely, ego-resiliency showed significant positive correlations with parenting style $(\mathrm{r}=.274, p<.01)$ and its sub-variables $(\mathrm{r}=.061 \sim 442, p<.01)$ except for inconsistency $(\mathrm{r}=-.073, p<.01)$ and excessive interference $(\mathrm{r}=-.050, p<.05)$. Also, ego-resiliency positively correlated with peer attachment $(\mathrm{r}=.452, p<.01)$ and its sub-variables $(\mathrm{r}=.469 \sim .477, p<.01)$ except for alienation $(\mathrm{r}=-.140, p<.01)$. Besides, ego-resiliency had positive relationships with school adjustment ( $\mathrm{r}=.543$, $p<.01)$ and all its sub-variables(r=.369 .520, $p<.01)$. In result, as ego-resiliency had significant positive correlations with parenting style, peer attachment, school adjustment, and almost all their sub-variables, it means that the higher ego-resiliency becomes, in general, the higher parenting style, peer attachment, and school adjustment become.

Second, supervision, affection, and rational explanation, the positive sub-variables of parenting style, positively correlated with each other $(\mathrm{r}=.417 \sim .668, p<.01)$ whereas they had negative relationships with inconsistency and excessive interference ( $\mathrm{r}=-.116 \sim .266, p<.01)$, the negative sub-variables of parenting style. An unreasonable expectation, the negative sub-variables of parenting style, didn't significantly correlate with supervision and rational explanation $(\mathrm{r}=-.022 \sim .014, p>.05)$, had negative relationships with total parenting style $(\mathrm{r}=-.668, p<.01)$ and affection $(\mathrm{r}=-.054$, $p<.05)$, and positively related to inconsistency and excessive interference $(\mathrm{r}=.557 \sim .701, p<.01)$.

Further, parenting style had significant positive relationships with peer attachment $(\mathrm{r}=.460, p<.01)$ and its sub-variables $(\mathrm{r}=.315 \sim .328, p<.01)$ exclusive of alienation ( $\mathrm{r}=-.406, p<.01)$. In detail, supervision, affection, and rational explanation the positive sub-variables of parenting style, significantly, positively related to communication and trust ( $\mathrm{r}=.357 \sim .479$, $p<.01)$ except for alienation. ( $\mathrm{r}=-.067 \sim .137, p<.01)$. On the other hand, inconsistency and excessive interference had negative correlations with communication and trust ( $\mathrm{r}=-.096 \sim-.119, p<.01)$ excluding alienation $(\mathrm{r}=.410 \sim .414, p<.01)$. The unreasonable expectation had insignificant relationships with communication and trust $(\mathrm{r}=.012 \sim .024, p>.05)$ except for alienation $(\mathrm{r}=.349, p<.01)$. Besides, parenting style had significant positive correlations with school adjustment $(\mathrm{r}=.437, p<.01)$ and its sub-variables $(\mathrm{r}=.262 \sim .456, p<.01)$. To be specific, supervision, affection, and rational explanation showed the significant positive correlations with school adjustment $(\mathrm{r}=.459 \sim .529, p<.01)$ and all its sub-variables $(\mathrm{r}=.315 \sim .480, p<.01)$. On the contrary, inconsistency and excessive interference had significant negative correlations with school adjustment $(\mathrm{r}=-.187 \sim-.204, p<.01)$ and all its sub-variables $(\mathrm{r}=-.066 \sim-.254, p<.01)$. Unreasonable expectation had insignificant correlations with the sub-variables of school adjustment $(\mathrm{r}=-.012 \sim .035$, $p>.01)$ except for friendship ( $\mathrm{r}=-.099, p<.01)$. As parenting style positively related to peer attachment and school adjustment, it implies that the higher parenting style becomes, the higher peer attachment and school adjustment become. Nonetheless, the sub-variables of parenting style showed somewhat different relationships with peer attachment and school adjustment and their sub-variables.

Lastly, Peer attachment and its sub-variables positively related to each other $(\mathrm{r}=.790 \sim 842, p<.01)$ except for alienation $(\mathrm{r}=-.197 \sim-.666, p<.01)$. Furthermore, peer attachment showed significant positive correlations with school adjustment $(\mathrm{r}=.483, p<.01)$ and all its sub-variables $(\mathrm{r}=.322 \sim .574, p<.01)$. More specifically, the sub-variables of peer attachment excluding alienation ( $\mathrm{r}=-.057 \sim-280, p<.05 \sim .01)$ had a significant positive relationship with school adjustment and all its sub-variables ( $\mathrm{r}=.318 \sim .547, p<.01)$. Considering that peer attachment and its sub-variables except for alienation had substantial correlations with school adjustment and all its factors, it indicates that the higher peer attachment except for alienation becomes, the higher school adjustment becomes. 
Table 1. Descriptive data and Pearson's correlation coefficients between variables

\begin{tabular}{|c|c|c|c|c|c|c|c|c|c|c|c|c|c|c|c|c|c|}
\hline & 1 & 2 & $2 a$ & $2 b$ & $2 c$ & $2 \mathrm{~d}$ & $2 \mathrm{e}$ & $2 \mathrm{f}$ & 3 & $3 a$ & $3 b$ & $3 c$ & 4 & $4 a$ & $4 b$ & $4 \mathrm{c}$ & $4 d$ \\
\hline 1 & 1 & & & & & & & & & & & & & & & & \\
\hline 2 & $.274^{* *}$ & 1 & & & & & & & & & & & & & & & \\
\hline $2 \mathrm{a}$ & $.346^{* *}$ & $.483^{* *}$ & 1 & & & & & & & & & & & & & & \\
\hline $2 b$ & $.442^{* *}$ & $.656^{* *}$ & $.557^{* *}$ & 1 & & & & & & & & & & & & & \\
\hline $2 c$ & $.392^{* *}$ & $.553^{* *}$ & $.417^{* *}$ & $.668^{* *}$ & 1 & & & & & & & & & & & & \\
\hline $2 d$ & $-.073^{* *}$ & $-.733^{* *}$ & $-.147^{* *}$ & $-.245^{* *}$ & $-.151^{* *}$ & 1 & & & & & & & & & & & \\
\hline $2 e$ & $.061^{* *}$ & $-.668^{* *}$ & .014 & $-.054^{*}$ & -.022 & $.557^{* *}$ & 1 & & & & & & & & & & \\
\hline $2 \mathrm{f}$ & $-.050^{*}$ & $-.803^{* *}$ & $-.116^{* *}$ & $-.266^{* *}$ & $-.171^{* *}$ & $.650^{* * *}$ & $.701^{* *}$ & 1 & & & & & & & & & \\
\hline 3 & $.452^{* *}$ & $.460^{* *}$ & $.372^{* *}$ & $.444^{* *}$ & $.340^{* *}$ & $-.299^{* *}$ & $-.157^{* *}$ & $-.280^{* *}$ & 1 & & & & & & & & \\
\hline $3 a$ & $.469^{* *}$ & $.328^{* *}$ & $.386^{* *}$ & $.479^{* *}$ & $.402^{* *}$ & $-.116^{* *}$ & .024 & $-.096^{* *}$ & $.819^{* *}$ & 1 & & & & & & & \\
\hline $3 b$ & $.477^{* *}$ & $.315^{* * *}$ & $.373^{* * *}$ & $.451^{* *}$ & $.357^{* *}$ & $-.119^{* *}$ & .012 & $-.100^{* *}$ & $.842^{* *}$ & $.790^{* * *}$ & 1 & & & & & & \\
\hline $3 c$ & $-.140^{* *}$ & $-.406^{* *}$ & $-.132^{* *}$ & $-.137^{* *}$ & $-.067^{* *}$ & $.414^{* *}$ & $.349^{* *}$ & $.410^{* *}$ & $-.666^{* * *}$ & $-.197^{* *}$ & $-.236^{* *}$ & 1 & & & & & \\
\hline 4 & $.543^{* *}$ & $.437^{* * *}$ & $.488^{* *}$ & $.529^{* *}$ & $.459^{* *}$ & $-.204^{* *}$ & -.027 & $-.187^{* *}$ & $.483^{* *}$ & $.506^{* *}$ & $.479^{* * *}$ & $-.172^{* *}$ & 1 & & & & \\
\hline $4 a$ & $.457^{* *}$ & $.359^{* * *}$ & $.412^{* *}$ & $.426^{* *}$ & $.370^{* * *}$ & $-.194^{* *}$ & -.012 & $-.147^{* *}$ & $.367^{* *}$ & $.387^{* *}$ & $.339^{* * *}$ & $-.149^{* * *}$ & $.810^{* *}$ & 1 & & & \\
\hline $4 b$ & $.369^{* *}$ & $.353^{* *}$ & $.417^{* *}$ & $.405^{* *}$ & $.357^{* *}$ & $-.168^{* *}$ & -.032 & $-.152^{* *}$ & $.322^{* *}$ & $.356^{* *}$ & $.318^{* *}$ & $-.100^{* *}$ & $.810^{* *}$ & $.565^{* *}$ & 1 & & \\
\hline $4 c$ & $.520^{* *}$ & $.456^{* *}$ & $.437^{* *}$ & $.480^{* *}$ & $.401^{* *}$ & $-.254^{* *}$ & $-.099^{* *}$ & $-.247^{* *}$ & $.574^{* *}$ & $.531^{* *}$ & $.547^{* *}$ & $-.280^{* *}$ & $.789^{* *}$ & $.593^{* *}$ & $.572^{* *}$ & 1 & \\
\hline $4 d$ & $.408^{* *}$ & $.262^{* *}$ & $.315^{* *}$ & $.395^{* *}$ & $.348^{* * *}$ & $-.066^{* *}$ & .035 & $-.080^{* *}$ & $.324^{* *}$ & $.371^{* *}$ & $.361^{* *}$ & $-.057^{*}$ & $.789^{* *}$ & $.477^{* *}$ & $.475^{* *}$ & $.497^{* *}$ & 1 \\
\hline$M$ & 42.12 & 62.86 & 10.23 & 13.16 & 9.18 & 9.44 & 13.72 & 12.55 & 28.44 & 9.63 & 9.79 & 8.99 & 62.94 & 15.06 & 15.99 & 16.21 & 15.68 \\
\hline SD & 6.68 & 8.54 & 1.59 & 2.17 & 1.79 & 2.08 & 2.55 & 2.66 & 4.19 & 1.66 & 1.74 & 2.05 & 8.20 & 2.67 & 2.52 & 2.12 & 2.95 \\
\hline Skewness & .089 & .189 & -.697 & -.419 & -.298 & .329 & .174 & .365 & -.057 & -.083 & -.350 & .711 & .174 & .024 & -.008 & .126 & -.256 \\
\hline Kurtosis & -.103 & -.423 & .381 & -.146 & .151 & -.112 & -.122 & -.099 & .065 & -.083 & .102 & .535 & -.475 & -.154 & -.201 & -.589 & -.155 \\
\hline
\end{tabular}

(1: ego-resiliency, 2: parenting style, 2a: supervision, 2b: affection, 2c: rational explanation, 2d: inconsistency, 2e: unreasonable expectation, 2f: excessive interference, 3: peer attachment, 3a: communication, 3b: trust, 3c: alienation, 4: school adjustment, 4a: learning activity, 4b: school rule, 4c: friendship, 4d: teacher-student relationship)

**Correlation is significant at the 0.01 level (2-tailed).

*Correlation is significant at the 0.05 level (2-tailed).

\subsection{The Results of the Regression Analysis}

Before performing the regression analysis, this article tested multicollinearity and independence of errors to check whether the data satisfied the assumptions of regression analysis or not. We calculated the tolerance value and variance inflation factor (VIF) to verify multicollinearity while producing Durbin-Watson statistic to test the independence of errors. As a result, there was no multicollinearity between any independent variables in that the tolerance values ranged from .349 to .1 .000 and VIFs were between 1.000 and 2.869. Since the Durbin-Watson statistic was 1.989 near 2, there was no autocorrelation in residuals. Because of meeting two assumptions, this study performed a hierarchical multiple regression to verify the relative predictive power of different variable groups on school adjustment and its sub-variables, and the result of the analysis is as follows. 
Table 2. The result of hierarchical multiple regression on school adjustment

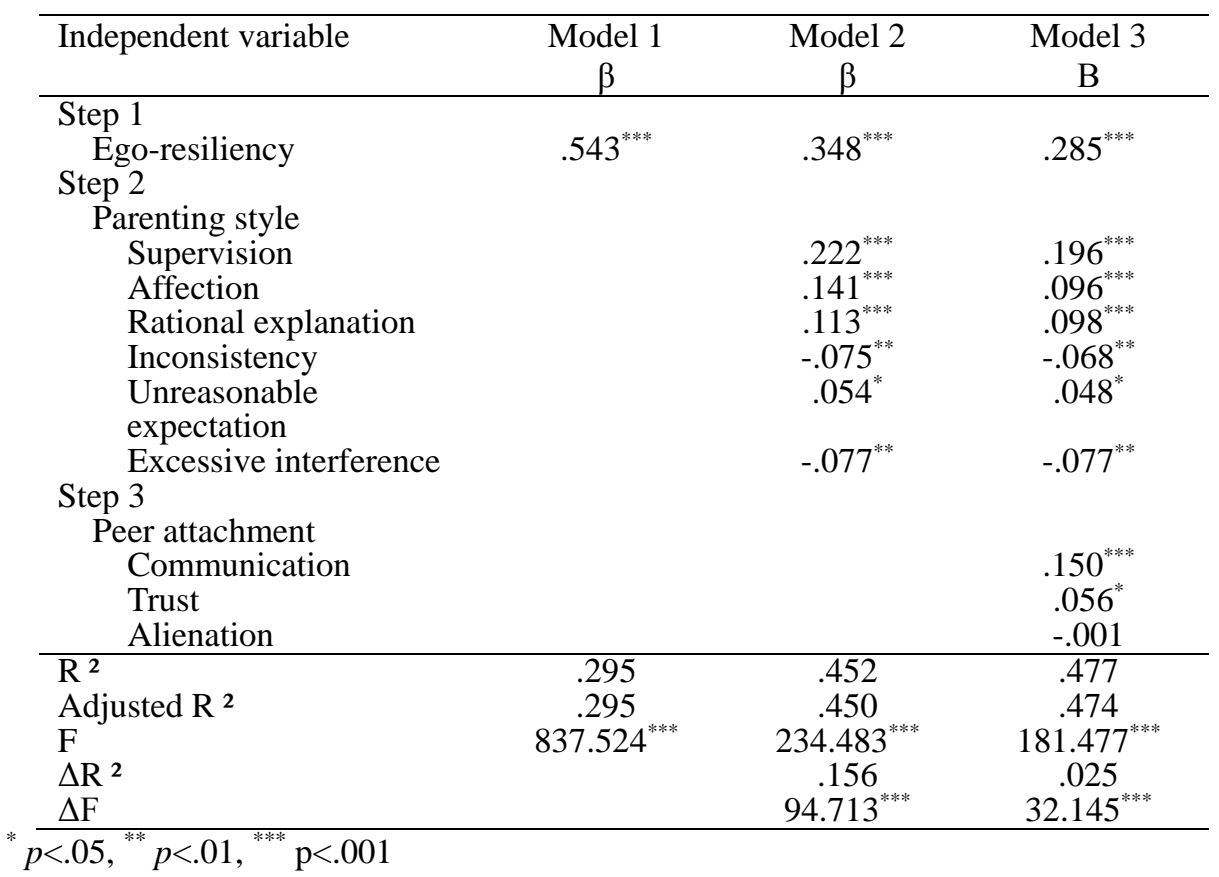

Table 2 showed the results of multiple regression analysis on total school adjustment, and specific results were as follows. In the first step, the model 1 putting only ego-resiliency as a significant single predictor $(\beta=.543, p<.01)$ accounted for $29.5 \%$ of total school adjustment $(\mathrm{F}=837.524, p<.001)$. In the second step, the model 2 explained $45.0 \%$ of total school adjustment $(\mathrm{F}=234.483, p<.001)$ by adding a predictive power of $15.6 \%$ thanks to parenting style. The analysis result of sub-variables indicated supervision $(\beta=.222, p<.001)$, affection $(\beta=.141, p<.001)$, rational explanation $(\beta=.113, p<.001)$, inconsistency $(\beta=-.075, p<.01)$, unreasonable expectation $(\beta=.054, p<.05)$, and excessive interference $(\beta=-.077, p<.01)$ as significant predictors of total school adjustment. Ego-resiliency still had a significant predictive power $(\beta=.348, p<.01)$ after putting parenting style into the model 2 . In the third step, as a result of adding into peer attachment, the model 3 predicted $47.4 \%$ of total school adjustment $(\mathrm{F}=181.477, p=.000)$ by increasing predictive power of $2.5 \%$. Of its sub-variables, communication $(\beta=.150, p<.001)$ and trust $(\beta=.056, p<.05)$ excluding alienation significantly predicted total school adjustment. In the third step, having significant explanatory power in the second step, ego-resiliency $(\beta=.285, p<.001)$ and all sub-variables of parenting style still significantly predicted total school adjustment. By sub-variables, supervision $(\beta=.196, p<.001)$, affection $(\beta=.096, p<.001)$, rational explanation $(\beta=.098$, $p<.001)$, inconsistency $(\beta=-.068, p<.01)$, unreasonable expectation $(\beta=.048, p<.05)$, and excessive interference $(\beta=-.077$ $p<.01)$ significantly explained total school adjustment. In result, each variable had significant predictive power (Adjusted $\mathrm{R}^{2}$ ) on school adjustment in order of ego-resiliency, parenting style, and peer attachment. In detail, individual sub-variables had significant predictive value ( $\beta$ value) to school adjustment in order of ego-resiliency, supervision, communication, rational explanation, affection, excessive interference, inconsistency, trust, and unreasonable expectation.

Subsequently, for analyzing the explanatory power of predictors on each sub-variable of school adjustment, the current article presents the analysis results in order of learning activity, school rule, friendship, and teacher-student relationship. First, model 1 putting only ego-resiliency $(\beta=.457, p<.01)$ in explained $20.8 \%(\mathrm{~F}=527.407, p<.001)$ of learning activity (Appendix A). In the second step, model 2 predicted $31.5 \%$ of learning activity $(\mathrm{F}=132.285, p<.001)$ by increasing contribution of $10.8 \%$ thanks to the parenting style. To be more specific, the analysis result confirmed supervision ( $\beta=.199, p<.001)$, affection $(\beta=.086, p<.001)$, rational explanation $(\beta=.088, p<.001)$, inconsistency $(\beta=-.120, p<.01)$, and unreasonable expectation $(\beta=.070, p<.05)$ as significant predictors of learning activity. Ego-resiliency still had a significant predictive power $(\beta=.300, p<.01)$ despite inserting parenting style into the model 2 . In the third step, as a result of adding into peer attachment, model 3 predicted $32.3 \%$ of learning activity ( $\mathrm{F}=96.431, p=.000$ ) by improving the predictive power of $0.9 \%$. Of its sub-variables, communication $(\beta=.146, p<.001)$ significantly predicted learning activity. In the third step, having significant predictive power in the second step, ego-resiliency $(\beta=.274, p<.001)$ and most sub-variables of parenting style significantly predicted learning activity. By sub-variables, supervision $(\beta=.187$, $p<.001)$, affection $(\beta=.067, p<.001)$, rational explanation $(\beta=.079, p<.001)$, inconsistency $(\beta=-.114, p<.01)$, and unreasonable expectation $(\beta=.057, p<.05)$ significantly predicted learning activity. Consequently, each variable had significant explanatory power (Adjusted $\mathrm{R}^{2}$ ) to learning activity in order of ego-resiliency, parenting style, and peer 
attachment. In specific, individual sub-variables had significant predictive value ( $\beta$ value) to learning activity in order of ego-resiliency, supervision, communication, inconsistency, rational explanation, affection, and unreasonable expectation.

Second, model 1 putting only ego-resiliency $(\beta=.369, p<.01)$ in accounted for $13.6 \%$ ( $\mathrm{F}=315.726, p<.001)$ of school rule (Appendix B). In the second step, model 2 predicted $26.0 \%$ of school rule $(\mathrm{F}=101.576, p<.001)$ by improving the predictive power of $12.7 \%$ thanks to parenting style. Concretely, the analysis result indicated supervision $(\beta=.241$, $p<.001)$, affection $(\beta=.085, p<.001)$, rational explanation $(\beta=.103, p<.001)$, and inconsistency $(\beta=-.064, p<.01)$ as significant predictors of a school rule. Ego-resiliency still had a significant predictive power $(\beta=.198, p<.01)$ despite putting parenting style into the model 2 . In the third step, as a result of adding peer attachment, model 3 predicted $26.9 \%$ of school rule $(\mathrm{F}=74.446, p<.001)$ by adding the predictive power of $0.9 \%$. Of its sub-variables, only communication $(\beta=.126, p<.001)$ significantly predicted school rule. In the third step, having significant predictive power in the second step, ego-resiliency $(\beta=.171, p<.001)$ and some sub-variables of parenting style significantly predicted school rule. To put it concretely, supervision $(\beta=.230, p<.001)$, rational explanation $(\beta=.090, p<.001)$, inconsistency $(\beta=-.069, p<.01)$, and excessive interference $(\beta=-.063, p<.05)$ significantly predicted school rule. Finally, each variable had significant predictive power (Adjusted $\mathrm{R}^{2}$ ) to school rule in order of ego-resiliency, parenting style, and peer attachment. In specific, individual sub-variables had significant predictive value ( $\beta$ value) to school rule in order of supervision, ego-resiliency, communication, rational explanation, and excessive interference.

Third, model 1 putting only ego-resiliency as a significant single predictor $(\beta=.520, p<.01)$ in predicted $27.0 \%$ $(\mathrm{F}=741.828, p<.001)$ of friendship (Appendix $\mathrm{C}$ ). In the second step, thanks to parenting style, model 2 predicted $40.4 \%$ of friendship ( $\mathrm{F}=194.562, p<.001)$ by increasing explanatory power of $13.5 \%$. Concretely, the analysis result identified supervision $(\beta=.192, p<.001)$, affection $(\beta=.114, p<.001)$, rational explanation $(\beta=.069, p<.001)$, inconsistency $(\beta=-.096$, $p<.01)$, and excessive interference $(\beta=-.114, p<.01)$ as significant predictors of friendship. Ego-resiliency still had a significant predictive power $(\beta=.363, p<.01)$ despite injecting the sub-variables of parenting style into the model 2 . In the third step, model 3 predicted $47.4 \%$ of friendship $(\mathrm{F}=74.446, p=.000)$ by adding the predictive power of $7.0 \%$ thanks to peer attachment. Communication $(\beta=.121, p<.001)$ and trust $(\beta=.196, p<.01)$ significantly, positively predicted friendship whereas alienation $(\beta=-.083, p<.01)$ significantly, negatively did it. In the third step, ego-resiliency $(\beta=.253$, $p<.001)$ and some sub-variables of parenting style, having significant explanatory power in the second step, still significantly accounted for friendship. By sub-variables, supervision $(\beta=.146, p<.001)$, rational explanation $(\beta=.057$, $p<.001)$, inconsistency $(\beta=-.067, p<.01)$, and excessive interference $(\beta=-.097, p<.05)$ significantly accounted for friendship. In result, each variable had significant predictive power (Adjusted $\mathrm{R}^{2}$ ) to friendship in order of ego-resiliency, parenting style, and peer attachment. In detail, individual sub-variables had significant predictive value ( $\beta$ value) to friendship in order of ego-resiliency, trust, supervision, communication, excessive interference, alienation, inconsistency, and rational explanation.

Fourth, model 1 putting only ego-resiliency $(\beta=.408, p<.01)$ in explained $16.6 \%$ ( $\mathrm{F}=399.316, p<.001)$ of teacher-student relationship (Appendix D). In the second step, thanks to parenting style, model 2 predicted $23.4 \%$ of teacher-student relationship ( $\mathrm{F}=88.501, p<.001)$ by adding the predictive power of $7.1 \%$. Concretely, the analysis result verified supervision $(\beta=.093, p<.001)$, affection $(\beta=.159, p<.001)$, rational explanation $(\beta=.096, p<.001)$ as significant predictors of the teacher-student relationship. Ego-resiliency still had a significant predictive power $(\beta=.265, p<.01)$ after inserting the sub-variables of parenting style into the model 2. In the third step, as a result of adding peer attachment, model 3 predicted $25.0 \%$ of the teacher-student relationship $(\mathrm{F}=67.608, p=.000)$ by increasing predictive power of $1.6 \%$. Of its sub-variables, communication $(\beta=.091, p<.001)$ and trust $(\beta=.080, p<.01)$ significantly explained the teacher-student relationship. In the third step, ego-resiliency $(\beta=.218, p<.001)$ and some sub-variables of parenting style, having significant explanatory power in the second step, significantly accounted for the teacher-student relationship. To be specific, supervision $(\beta=.075, p<.001)$, affection $(\beta=.121, p<.001)$, and rational explanation $(\beta=.083, p<.001)$ significantly accounted for the teacher-student relationship. Finally, each variable had significant predictive power (Adjusted $\mathrm{R}^{2}$ ) to the teacher-student relationship in order of ego-resiliency, parenting style, and peer attachment. In detail, individual sub-variables had significant explanatory power ( $\beta$ value) to the teacher-student relationship in order of ego-resiliency, affection, communication, rational explanation, supervision, and trust.

\section{Discussion}

The present study intended to identify the relative predictive power of ego-resiliency, parenting style, and peer attachment on South Korean middle school students' school adjustment. Here, focusing on this purpose of the present study, when we discuss the above findings with past works, it is as follows.

First of all, all the correlations between ego-resiliency, parenting style, peer attachment, and school adjustment were significantly positive. These outcomes agreed with existing studies because, to our knowledge, even though there was 
no study concurrently reporting relationships between four variables, there were many investigations indicating associations between two or three variables (Han \& Bang, 2017; Kim \& Jang, 2015; Noh, Heo, \& Choi, 2015; Song, Kim, \& Hwang, 2011; Laible, Carlo, \& Raffaelli, 2000; Eisenberg, Chang, Ma, \& Huang, 2009). The relationships between all the variables including ego-resiliency, parenting style, peer attachment, and school adjustment seem to uphold the concept of Bronfenbrenner's mesosystem (1979) which means the interaction among microsystems such as individual, family, peer, and school. Also, of all the relationships, the positive correlations between all the predictors and school adjustment imply that adolescents with higher ego-resiliency, parenting style, and peer attachment are likely to adapt to the school environment better.

Subsequently, the sub-variables of them had significant correlations with each other except for unreasonable expectation. In detail, of the sub-variables showing significant correlations, inconsistency, excessive interference, and alienation negatively related to other sub-variables. This empirical evidence implies that almost all sub-variables exclusive of unreasonable expectation have a substantial influence on each other whether it is positive or not. Moreover, these findings provide the possibility that adolescents who have higher ego-resiliency, supervision, affection, rational explanation, communication, and trust and lower inconsistency, excessive interference, and alienation show higher school adjustment and its sub-variables. These results are in line with the prior studies (Chang et al., 2011; Kim \& Lee, 2015; Shin \& Son, 2016; Simons-Morton \& Chen, 2009; Williams et al., 2012) presenting substantial correlations between at least three sub-variables or more relating to the sub-variables of the current study.

One thing to note in these outcomes is the unreasonable expectation belonging to the negative sub-variables of parenting style. To be specific, unreasonable expectation had inconsistent relationships with other sub-variables within parenting style. That is, unreasonable expectation didn't significantly correlate with supervision and rational explanation, had negative associations with total parenting style and affection, and positively related to inconsistency and excessive interference. Further, unreasonable expectation is also inconsistent with sub-variables outside parenting style. That is, it positively related to ego-resiliency and alienation, had negative relationships with total peer attachment and friendship, and had insignificant correlations with the rest of sub-variables. Since the unreasonable expectation is inconsistent with the sub-variables both within and outside parenting style, as described above, we examine these conflicting findings in the following. First of all, it requires examining the construct of an unreasonable expectation in that it is inconsistent with even other sub-variables within parenting style. Outside of that, there is a need to identify cultural context concerning unreasonable expectation since these outcomes that ego-resiliency positively related to unreasonable expectation contrast with the works of Taylor, Eisenberg, Spinrad, and Widaman (2013) that there was no correlation between ego-resiliency and unreasonable expectation. Continually, these findings are contrary to even Simons-Morton and Chen's study (2009) that authoritative parenting facilitated school engagement. Here, it may attribute these inconsistent consequences to the difference between the scales measuring the authoritative parenting in other countries and the unreasonable expectation of the present study, as prior mentioned about the construct of the scale. For example, for South Korean adolescents, the unreasonable expectation of this work may be too high or low to predict better achievement and aspiration (Kirk, Lewis-Moss, Nilsen, \& Colvin, 2011; Neuenschwander, Vida, Garrett, \& Eccles, 2007). Dissenting the socio-cultural view, however, Williams et al. (2012) posed the developmental possibility pointing out that conflicting findings may not show in other age groups.

Second, as the result of hierarchical regression analysis, predictors significantly, positively explained school adjustment and all its sub-variables (learning activity, school rule, friendship, and teacher-student relationship) in order of ego-resiliency, parenting style, and peer attachment. To our knowledge, since there is no direct comparable research result putting three predictors in at once, this empirical evidence is discussed from a slightly different angle. First, it also confirmed the idea of mesosystem in that the current work verified the interactions between each predictor in the individual, family, and peer dimension and criterion variable in school dimension (Bronfenbrenner, 1979). Moreover, it suggests that the ego-resiliency, parenting style, and peer attachment influenced adolescents' school adjustment at a different rate according to the proximity from the individual, albeit all belong to the same microsystems. Besides, seeing the outcomes of this work in the eyes of Gibson (1966), adolescents with higher ego-resiliency, parenting style, and peer attachment would fulfill the affordances required for school adjustment. Affordances, being shaped by the interaction between the self and outside world, mean the ability to deal with objects or peoples around us for suiting us better (Gibson, 1979). Consequently, according to Gibson, adolescents, who built ego-resiliency and then ensured even the affordances by way of appropriate parenting style and peer attachment, will accommodate themselves readily to school.

By the sub-variables of predictors, even if there is no vast difference compared to predictors themselves, their relative contribution was somewhat different according to criterion variable and its sub-variables. Since little was known about the comparable study concerned the relative predictive power, as we know, we will present some analysis results on the explanatory power of the sub-variables of predictors and then discuss. First, ego-resiliency showed the highest predictive power on the sub-variables of criterion variable except for secondly explaining the school rule. Second, the 
supervision and rational explanation substantially, positively predicted all sub-variables of criterion variable and the affection significantly predicted the learning activity and the teacher-student relationship. In contrast, unreasonable parenting positively explained the learning activity while the inconsistency negatively explained the learning activity, school rule, and friendship, and the excessive interference made a negative prediction for the school rule and friendship. Third, the communication significantly explained the learning activity, school rule, friendship, and the teacher-student relationship. Also, the trust positively predicted friendship and, especially, made the second prediction for the friendship whereas alienation negatively predicted friendship. Above outcomes are discussed with the previous studies in order of ego-resiliency, parenting style, and peer attachment as follow.

Ego-resiliency showed the very high contribution to all the sub-variables of criterion variable. In other words, ego-resiliency showed the highest predictive power on the learning activity, friendship, and teacher-student relationship except for secondly predicting the school rule. This result has something to do with the past investigations (Eisenberg et al., 1997; Eisenberg, Spinrad, \& Morris, 2002; Gjerde, Block, \& Block, 1986; Juffer, Stams, \& Ijzendoorn, 2004; Taylor et al., 2013). In reality, as the resilient adolescents revealed broader motivational and affective functions (Gjerde, Block, \& Block, 1986), they tend to participate in the learning activity actively and overcome the difficulty relating to learning flexibly (Shin \& Son, 2016). Primarily, the ego-resiliency connotes adaptation in the concept itself (Block \& Block, 1980). Therefore, if adolescents' ego-resiliency is high, they would show more behavior regulation and less problem behavior and follow the school rule (Eisenberg, Spinrad, \& Morris, 2010; Juffer, Stams, \& Ijzendoorn, 2004). Besides, the ego-resiliency relates to the flexibility and self-regulation (Shin \& Son, 2016). As such, adolescents with high ego-resiliency have the competent social functioning and prosocial behavior and, in turn, maintain smooth friendship and teacher-student relationship (Eisenberg et al., 1997; Taylor et al., 2013). Considering above discussion, the counseling programs or educational activities, to promote adolescents' school adjustment, will need to contain various activities strengthening the ego-resiliency of adolescents rather than external factors.

In parenting style, the sub-variables of the predictor revealed different explanatory powers. For example, the supervision and rational explanation significantly, positively predicted all the sub-variables of criterion variable and, moreover, the supervision made the highest prediction for the school rule. This evidence means that the $7^{\text {th }}$ graders, who need much more learning and face much more physical, emotional, and environmental changes, regarded the supervision and rational explanation as beneficial interest toward themselves (Shin \& Son, 2016). In reality, Barnard (2004) demonstrated that parent involvement not only was associated with school success in childhood but also showed a long-term effect until high school. In result, the supervision and rational explanation appear to meet adolescents' realistic need. Notably, the supervision had the highest prediction for the school rule, and this evidence also suggests that the relationship with parents may decrease negative behaviors such as conduct problems and lead to abiding by the school rule (Oldfield et al., 2016; Williams et al., 2012). Besides, the affection significantly predicted the learning activity and, especially, made the second explanation for the teacher-student relationship. These consequences imply that adolescents considered the affection as the interest toward their learning activity and affection allows adolescents to acquire affordances readily required for the teacher-student relationship. In this sense, Rosenzweig (2001) also pointed out that emotional support and authoritative parenting was important for adolescents' adjustment.

On the other hand, inconsistency negatively explained the learning activity, school rule, and friendship and excessive interference negatively explained the school rule and friendship. These results are consistent with earlier works (Chang et al., 2011; Kim and Lee, 2015; Shin \& Son, 2016) and imply that parental inconsistency and excessive interference disrupt adolescents' learning activity, school rule, and friendship. This empirical evidence, reflecting the adverse effect of parenting style, seems to be due to growing autonomy according to adolescents' development and, in turn, evoke the resistance of adolescents (Allen, 2008; Cho, 2013; Chang et al., 2011; Laible et al., 2000; Oldfield et al., 2016; Sasikala \& Cecil, 2016). Besides, the unreasonable parenting positively explained the learning activity, and these consequences imply that the unreasonable parenting met adolescents' realistic need willy-nilly at the time of which study is crucial. These findings support the concept that adolescents may regard the unreasonable expectation as a necessary evil enough to predict better achievement and aspiration (Kirk, Lewis-Moss, Nilsen, \& Colvin, 2011; Neuenschwander, Vida, Garrett, \& Eccles, 2007). Nonetheless, it requires examining the inconsistent investigations that unreasonable monitoring and caring may decrease or increase adolescents' motivation, reflecting mediating variables, developmental level, and even socio-cultural context (Hong, Hwang, Kuo, \& Hsu, 2015; Odong et al., 2016; Pinquart, 2015; Shin \& Son, 2016). Together, for improving adolescents' school adjustment, it requires parent education and counseling to promote the positive parenting style and to reduce the negative parenting style at the same time. In case of the unreasonable parenting, particularly, there is a need to clarify the conflicting results considering the mediating variables, the developmental level, and socio-cultural context. When reflecting developmental level, unlike this article extracting only the cross-sectional data of $7^{\text {th }}$ graders in 2016, it is required to use the panel data themselves which encompass the cross-sectional and longitudinal data for establishing unreasonable parenting thoroughly exclusive of the cohort effect. 
Of peer attachment, the communication significantly predicted the learning activity, school rule, friendship, and teacher-student relationship. This result means that the interactions with peers allowed them to gain information and shape an attitude related to achievement, a prosocial behavior, an interpersonal competence, and a position toward school (Altermatt, 2011; Baytemir, 2016; Oldfield et al., 2016; Ryan, 2000; Sasikala \& Cecil, 2016). Also, the trust made the second prediction for the friendship and significantly predicted the teacher-student relationship. Though this confidential relationship with peers may shape affordances needed for the teacher-student connection, it may make adolescents acquire anti-social behavior in conjunction with the communication (Demanet \& Houtte, 2012; Tomada et al., 2005). Thus, it requires being mindful of a few studies, that cast doubt on the adverse effect of a peer relationship, pointing out that higher peer attachment related to higher rates of school misconduct (Demanet \& Houtte, 2012). Lastly, the alienation negatively predicted the friendship, and this result is consistent with the work of Chang et al. (2011). Hence, the ways to reduce alienation for enhancing school adjustment also have to be included in education activities and counseling programs. Together, since peers have the growing importance for adolescents as they advance through school, the program to promote school adjustment needs to include various activities using peer relationships.

\section{Conclusion}

As discussed above, the present study verified the relative predictive power of predictors on the school adjustment. The analysis results by predictive variables made the significant positive prediction for the school adjustment and its sub-variables in order of ego-resiliency, parenting style, and peer attachment. Although we had limitations about constitution of variables and sub-variables since the existing data was used, the outcomes suggest a guideline to follow when further research constructs educational activities or counseling programs for enhancing school adjustment. In other words, though various microsystems such as individual, family, and peer influence each other, as the effect of predictors on the school adjustment presented in order of ego-resiliency, parenting style, and peer attachment, it is required to consider the priority in designing educational activities or counseling programs. Also, though the analysis results by sub-variables of predictive variables showed a similar trend to the analysis results by predictive variables themselves, the supervision for the school rule, trust for friendship, and affection for the teacher-student connection became somewhat weightier. These outcomes suggest that the focus can be a little bit different according to a specific goal of education activities or counseling programs or students' characteristics relating to school adjustment. Along with this, there is a need to design parent education and counseling which increase the positive parenting style while decreasing the negative parenting style in the context of South Korea. Finally, to enhance school adjustment of adolescents facing various and difficult developmental task, it expects that these outcomes provide a meaningful data in constructing educational activities and counseling programs and even consulting with school parents. Also, it is useful that the present work re-confirmed the necessity to examine the items of the scale measuring unreasonable expectation. Based on reviewing the items of the scale, the future research is expected to clarify the incompatible investigations of unreasonable expectation considering mediating variables, adolescents' developmental level, and cultural context of each country.

\section{Acknowledgments}

I thank Professor You-me Kim in Seoul National University of Education for her organized advice and supervision and National Youth Policy Institute (NYPI) for permission to use the data of the Korean Children and Youth Panel Survey (KCYPS).

\section{References}

Al-Hendawi, M. (2013). Temperament, school adjustment, and academic achievement: Existing research and future directions. Educational Review, 65(2), 177-205. https://doi.org/10.1080/00131911.2011.648371

Allen, J. P. (2008). The attachment system in adolescence. New York: Guilford Press.

Altermatt, E. R. (2011). Capitalizing on academic success: Students' interactions with friends as predictors of school adjustment. Journal of Early Adolescence, 31(1), 174-203. https://doi.org/10.1177/0272431610379414

Armsden, G. C., \& Greenberg, M. T. (1987). The inventory of parent and peer attachment: Individual differences and their relationship to psychological well-being in adolescence. Journal of Youth and Adolescence, 16(5), 427-454. https://doi.org/10.1007/BF02202939

Arnett, J. J. (2000). Emerging adulthood: A theory of development from the late teens through the twenties. American Psychologist, 55(5), 469-480. https://doi.org/10.1037/0003-066X.55.5.469

Bardack, S., Herbers, J. E., \& Obradović, J. (2017). Unique contributions of dynamic versus global measures of parent-child interaction quality in predicting school adjustment. Journal of Family Psychology, 31(6), 649-658. https://doi.org/10.1037/fam0000296 
Barnard, W. M. (2004). Parent involvement in elementary school and educational attainment. Children and Youth Services Review, 26(1), 39-62. https://doi.org/10.1016/j.childyouth.2003.11.002

Baytemir, K. (2016). The mediation of interpersonal competence in the relationship between parent and peer attachment and subjective well-being in adolescence. Education and Science, 41(186), 69-91. https://doi.org/10.15390/EB.2016.6185

Betts, L. R., Trueman, M., Chiverton, L., Stanbridge, A., \& Stephens, J. (2013). Parental rearing style as a predictor of attachment and psychosocial adjustment during young adulthood. Journal of Social and Personal Relationships, 30(6), 675-693. https://doi.org/10.1177/0265407512465998

Bierman, K. L. (1994). School adjustment. In R. J. Corsini (ed.), Encyclopedia of psychology. A Wiley-Interscience Publication, John Wiley \& Sons. 150-179.

Block, J. H., \& Block, J. (1980). The role of ego-control and ego-resiliency in the organization of behavior. In W. A. Collins (Ed.), The Minnesota symposia on child psychology (Vol. 13, pp. 39-101). Hillsdale: Lawrence Erlbaum.

Block, J., \& Kremen, A. M. (1996). IQ and ego-resiliency: Conceptual and empirical connections and separateness. Journal of Personality and Social Psychology, 70(2), 349-361. https://doi.org/10.1037/0022-3514.70.2.349

Bronfenbrenner, U. (1979). The ecology of human development: Experiments by nature and design. Cambridge, MA: Harvard University Press.

Chang, S., Song, S., \& Cho, M. (2011). The mobile phone dependency, perceived parenting style, peer attachment as predictors school adjustment of middle school students. Korean Journal of Youth Studies, 18(12), 431-451.

Chen, X., Dong, Q., \& Zhou, H. (1997). Authoritative and authoritarian parenting practices and social and school performance in Chinese children. International Journal of Behavioral Development, 21(4), 855-873. https://doi.org/10.1080/016502597384703

Cho, H. (2013). A study on factors affecting school adjustment of middle school students. Evangelism and practice, 51(1), 309-336.

Cho, J. (2012). Identifying latent classes in adolescents' school adjustment and testing eco-system variables as predictors of latent classes. Studies on Korean Youth, 23(1), 277-309.

Coleman, M., Ganong, L., \& Fine, M. (2000). Reinvestigating remarriage: Another decade of progress. Journal of Marriage and Family, 62(4), 1288-1307. https://doi.org/10.1111/j.1741-3737.2000.01288.x

Darling, N., \& Steinberg, L. (1993). Parenting style as context: An integrative model. Psychology Bulletin, 113, 487-496. https://doi.org/10.1037/0033-2909.113.3.487

Demanet, J., \& Van Houtte, M. (2012). School belonging and school misconduct: The differing role of teacher and peer attachment. Journal of Youth Adolescence, 41, 499-514. https://doi.org/10.1007/s10964-011-9674-2

Eisenberg, N., Chang, L., Ma, Y., \& Huang, X. (2009). Relations of parenting style to Chinese children's effortful control, ego resilience, and maladjustment. Development and Psychopathology, 21(2), 455-477. https://doi.org/10.1017/S095457940900025X

Eisenberg, N., Guthrie, I. K., Fabes, R. A., Reiser, M., Murphy, B., Holgren, R., Maszk, P., \& Losoya, S. (1997). The relations of regulation and emotionality to resiliency and competent social functioning in elementary school children. Child Development, 68(2), 295-311. https://doi.org/10.2307/1131851

Eisenberg, N., Spinrad, T. L., \& Morris, A. S. (2002). Regulation, resiliency, and quality of social functioning. Self and Identity, l(2), 121-128. https://doi.org/10.1080/152988602317319294

Elliot, G. R., \& Feldman, S. S. (1990). Capturing the adolescent experience. In S. S. Feldman and G. R. Elliot (Eds.), At the threshold: The developing adolescent. Cambridge: Harvard University Press.

Geum, J., Son, C., Chae, S., \& Kang, S. (2013). Middle school students' school-adjustment, and the relation between family and individual characteristics. Korean Journal of Youth Studies, 20(2), 119-143.

Gibson, J. J. (1966). The Senses Considered as Perceptual Systems. London: Allen and Unwin.

Gibson, J. J. (1979). The ecological approach to visual perception. Boston: Houghton Mifflin.

Gjerde, P. F., Block, J., \& Block, J. H. (1986). Egocentrism and ego-resiliency: Personality characteristics associated with perspective-taking from early childhood to adolescence. Journal of Personality and Social Psychology, 51(2), 423. https://doi.org/10.1037/0022-3514.51.2.423

Hall, G. E., \& Diperna, J. C. (2017). Childhood social skills as predictors of middle school academic adjustment. 
Journal of Early Adolescence, 37(6), 825-851. https://doi.org/10.1177/0272431615624566

Han, B., \& Bang, E. (2017). The ego resilience, and parental role responsibilities perceived by adolescents as predictors of school adjustment. Korean Journal of Youth Studies, 24(8), 273-304.

Heo, M. (2000). The study for the development and validation of 'parenting behavior inventory' perceived by adolescents (Doctoral dissertation). Retrieved from http://dcollection.ewha.ac.kr/ezpdfdrm/dCollection.jsp?sItemId=000000000625

Hong, J. C., Hwang, M. Y., Kuo, Y. C., \& Hsu, W. Y. (2015). Parental monitoring and helicopter parenting relevant to vocational student's procrastination and self-regulated learning. Learning and Individual Differences, 42, 139-146. https://doi.org/10.1016/j.lindif.2015.08.003

Huang, G. H. C., \& Gove, M. (2016). Asian parenting styles and academic achievement: Views from Eastern and Western perspectives. Education, 135(3), 389-397.

Hwang, M. (2010). The relationship between parent-peer attachment of multi-culture children and social anxiety (Master's thesis). Retrieved from http://pknu.dcollection.net/common/orgView/000001955817

Inam, A., Nomaan, S., \& Abiodullah, M. (2016). Parents' parenting styles and academic achievement of underachievers and high achievers at the middle school level. Bulletin of Education and Research, 38(1), 57-74.

Joo, G., \& Kwon, I. (2017). The relationship of youth activities satisfaction and school adaptation: The mediating effects of the sense of community. Korean Children \& Youth Panel Academic conference. Seoul, Korea.

Juffer, F., Stams, G. J. J., \& IJzendoorn, M. H. (2004). Adopted children's problem behavior is significantly related to their ego resiliency, ego control, and sociometric status. Journal of Child Psychology and Psychiatry, 45(4), 697-706. https://doi.org/10.1111/j.1469-7610.2004.00264.x

Keogh, B. K. (2003). Temperament in the classroom: Understanding individual differences. Baltimore, MD: Paul H. Brookes.

Keum, J., Son, C., Chae, S., \& Kang, S. (2013). Middle school students' school-adjustment, and the relation with family and individual characteristics. Korean Journal of Youth Society, 20(2), 119-143.

Kim, C., \& Lee, K. (2015). The mediating effects of ego-resilience on achievement-oriented parenting style, school adjustment and academic achievement as perceived by children. Family and Environment Research, 53(5), 503-517. https://doi.org/10.6115/fer.2015.040

Kim, J., \& Jang, I. (2015). Mediating effect of ego-resiliency and mental health between psychological home environment and adaptation to a school of early adolescents in schools with educational welfare priority project. The Journal of Korean Contents Association, 15(3), 467-476. https://doi.org/10.5392/JKCA.2015.15.03.467

Kirk, C. M., Lewis - Moss, R. K., Nilsen, C., \& Colvin, D. Q. (2011). The role of parent expectations on adolescent educational aspirations. Educational Studies, 37(1), 89-99. https://doi.org/10.1080/03055691003728965

Korea Joongang daily (2017). More unemployed men turn to gambling. Retrieved from http://koreajoongangdaily.joins.com/news/article/article.aspx?aid=3037323

Korean Ministry of Education. (2016). The notifier for school. http://www.schoolinfo.go.kr

Korean Ministry of Gender and Family. (2016). The third youth committee's data. 1-75.

Korean Youth Policy Institute. (2013). The survey on children and youth's rights in Korea.

Kwak, S. (2006). A structural equation modeling analysis of adolescents' school adjustment. Korean Journal of Sociology of Education, 16(1), 1-26.

Ladd, G. W. (1990). Having friends, keeping friends, making friends, and being liked by peers in the classroom: Predictors of children's early school adjustment? Child Development, 61(4), 1081-1100. https://doi.org/10.2307/1130877

Ladd, G. W., \& Price, J. M. (1987). Predicting children's social and school adjustment following the transition from preschool to kindergarten. Child development, 1168-1189. https://doi.org/10.2307/1130613

Laible, D. J., Carlo, G., \& Raffaelli, M. (2000). The differential relations of parent and peer attachment to adolescent adjustment. Journal of Youth and Adolescence, 29(1), 45-59. https://doi.org/10.1023/A:1005169004882

Laursen, B., \& Collins, W. A. (2012). Relationship pathways: From adolescence to young adulthood. CA: Sage. https://doi.org/10.4135/9781452240565

Lee, J., \& Kang, S. (2017). The relationship of positive and negative parenting style and school adjustment of a 
first-grader in elementary school: The mediating effects of parent-friend relationship and peer attachment. Korean Children and Youth Panel Academic conference. Seoul, Korea.

Liew, J., Cao, Q., Hughes, J. N., \& Deutz, M. H. F. (2018). Academic resilience despite early academic adversity: A three-wave longitudinal study on regulation-related resiliency, interpersonal relationships, and achievement in first to third grade, early education, and development.

Martin, R. P. (1994). Child temperament and common problems in schooling: Hypotheses about causal connections. Journal of School Psychology, 32(2), 119-134. https://doi.org/10.1016/0022-4405(94)90006-X

Mekonnen, M. A. (2017). Effects of family educational background, dwelling and parenting style on students' academic achievement: The case of secondary schools in Bahir Dar. Educational Research and Reviews, 12(18), 939-949.

Mestre, J. M., Guil, R., Lopes, P. N., Salovey, P., \& Gil-Olarte, P. (2006). Emotional intelligence and social and academic adaptation to school. Psicothema, 18, 112-117.

Min, B. (1991). The effects of school life adjustment and self-concept on academic achievement (Master's thesis).

Neuenschwander, M. P., Vida, M., Garrett, J. L., \& Eccles, J. S. (2007). Parents' expectations and students' achievement in two western nations. International Journal of Behavioral Development, 31(6), 594-602. https://doi.org/10.1177/0165025407080589

Noh, M., Heo, M., \& Choi, Y. (2015). The influence of parenting attitudes on adolescents' school adjustment: Mediating effects of ego resiliency and care. Journal of Korean Home Management Association, 33(2), 119-134. https://doi.org/10.7466/JKHMA.2015.33.2.119

Odong, A. A., Aloka, P. J. P., \& Raburu, P. (2016). Influence of parenting styles on the adolescent students' academic achievement in Kenyan day secondary schools. Journal of Education and Practice, 7(15), 101-108.

Oldfield, J., Humphrey, N., \& Hebron, J. (2016). The role of parental and peer attachment relationships and school connectedness in predicting adolescent mental health outcomes. Child and Adolescent Mental Health, 21(1), 21-29. https://doi.org/10.1111/camh.12108

Pinquart, M. (2015). Associations of parenting styles and dimensions with academic achievement in children and adolescents: A meta-analysis. Educational Psychology Review, 28, 475-493. https://doi.org/10.1007/s10648-015-9338-y

Rosenzweig, C. (2001). A Meta-Analysis of Parenting and School Success: The Role of Parents in Promoting Students' Academic Performance. Dissertation Abstracts International, 61(04), 1730B. (UMI No. 9968470)

Ryan, A. M. (2000). Peer groups as a context for the socialization of adolescents' motivation, engagement, and achievement in school. Educational Psychologist, 35(2), 101-111. https://doi.org/10.1207/S15326985EP3502_4

Ryan, A. M., \& Shim, S. S. (2008). An exploration of young adolescents' social achievement goals and social adjustment in middle school. Journal of Educational Psychology, 100, 672-687. https://doi.org/10.1037/0022-0663.100.3.672

Sakar, K., \& Ray, A. (2017). Study on the role of attachment with parents and peers and depressive symptoms on the reproductive health of adolescent boys and girls. Indian Journal of Health and Well-being, 8(8), 777-785.

Sasikala, S., \& Cecil, N. (2016). Parental bonding, peer attachment and psychological well-being among adolescents: A mediation analysis. Journal of Psychosocial Research, 11(1), 21-31.

SBS (2018. 4. 2). The weight of Korean rolling admission is too high...Will the college entrance system change? Retrieved from http://news.sbs.co.kr/news/endPage.do?news_id=N1004695025\&plink=ORI\&cooper=DAUM

Shin, S., \& Son, E. (2016). Longitudinal analysis of effects of parenting method and ego-resilience perceived by youth on adaptation to school. Korean Journal of Youth Studies, 23(12), 25-45. https://doi.org/10.21509/KJYS.2016.12.23.12.25

Simons-Morton, B., \& Chen, R. (2009). Peer and parent influences on school engagement among early adolescents. Youth \& Society, 4l(1), 3-25. https://doi.org/10.1177/0044118X09334861

Song, Y. K., Kim, Y. H., \& Hwang, S. S. (2011). Effects from the interaction of ego-resilience, social supports in the school adjustment of elementary school children. Korean Journal of Human Ecology, 20(1), 1-19. https://doi.org/10.5934/KJHE.2011.20.1.001

Spera, C. (2005). A review of the relationship among parenting practices, parenting styles, and adolescent school achievement. Educational Psychology Review, 17(2), 125-146. https://doi.org/10.1007/s10648-005-3950-1 
Stipek, D. (1997). Success in school-for a head start in life. In S. S. Luthar, J. A. Burack, D. Cicchetti, \& J. R. Weisz (Eds.), Developmental psychopathology: Perspectives on adjustment, risk, and disorder (pp. 75-92). New York, NY: Cambridge University Press.

Taylor, Z. E., Eisenberg, N., Spinrad, T. L., Eggum, N. D., \& Sulik, M. J., (2013). The relations of ego-resiliency and emotion socialization to the development of empathy and prosocial behavior across early childhood. Emotion, 13(5), 822-831. https://doi.org/10.1037/a0032894

The Korean Foundation for Prevention Youth Violence (2016). The survey on school violence in Korea.

Tomada, G., Schneider, B. H., de Domini, P., Greenman, P. S., \& Fonzi, A. (2005). Friendship as a predictor of adjustment following a transition to formal academic instruction and evaluation. International Journal of Behavioral Development, 29(4), 314-322. https://doi.org/10.1177/01650250544000099

Williams, K. E., Ciarrochi, J., \& Heaven, P. C. (2012). Inflexible parents, inflexible kids: A 6-year longitudinal study of parenting style and the development of psychological flexibility in adolescents. Journal of Youth Adolescence, 41, 1053-1066. https://doi.org/10.1007/s10964-012-9744-0

Xia, Y. R., Wang, C., Li, W., Wilson, S., Bush, K. R., \& Peterson, G. (2015). Chinese parenting behaviors, adolescent school adjustment, and problem behavior. Marriage \& Family Review, 51(6), 489-515. https://doi.org/10.1080/01494929.2015.1038408

Yates, T. M., Obradović, J., \& Egeland, B. (2010). Transactional relations across contextual strain, parenting quality, and early childhood regulation and adaptation in a high-risk sample. Development and Psychopathology, 22(3), 539-555. https://doi.org/10.1017/S095457941000026X

Yoo, S., \& Sim, H. (2002). Psychological protective factors in resilient adolescents in Korea. The Korean Journal of Educational Psychology, 16(4), 189-206. 
Appendix A. The result of hierarchical multiple regression on learning activity

\begin{tabular}{|c|c|c|c|}
\hline Independent variable & $\begin{array}{c}\text { Model } 1 \\
\beta\end{array}$ & $\begin{array}{c}\text { Model } 2 \\
\text { B }\end{array}$ & $\begin{array}{c}\text { Model } 3 \\
\text { B }\end{array}$ \\
\hline \multicolumn{4}{|l|}{ Step 1} \\
\hline Ego-resiliency & $.457^{* * * *}$ & $.300^{* * *}$ & $.274^{* * * *}$ \\
\hline \multicolumn{4}{|l|}{ Step 2} \\
\hline \multicolumn{4}{|l|}{ Parenting style } \\
\hline Supervision & & $.199^{* * *}$ & $.187^{* * * *}$ \\
\hline Affection & & $.086^{* *}$ & $.067^{*}$ \\
\hline Rational explanation & & $.088^{* * *}$ & $.079^{* *}$ \\
\hline Inconsistency & & $-.120^{* * *}$ & $-.114^{* * *}$ \\
\hline Unreasonable expectation & & $.070^{*}$ & $.057^{*}$ \\
\hline Excessive interference & & -.042 & -.039 \\
\hline \multicolumn{4}{|l|}{ Step 3} \\
\hline \multicolumn{4}{|l|}{ Peer attachment } \\
\hline Communication & & & $.146^{* * *}$ \\
\hline Trust & & & -.057 \\
\hline Alienation & & & -.017 \\
\hline $\mathrm{R}^{2}$ & .209 & .317 & .326 \\
\hline Adjusted $\mathrm{R}^{2}$ & .208 & .315 & .323 \\
\hline $\mathrm{F}$ & $527.407^{* * *}$ & $132.285^{* * * *}$ & $96.431^{* * *}$ \\
\hline$\Delta \mathrm{R}^{2}$ & & .108 & .009 \\
\hline$\Delta \mathrm{F}$ & & $52.772^{* * *}$ & $9.037^{* * *}$ \\
\hline
\end{tabular}

$\frac{\Delta \mathrm{F}}{{ }^{*} p<.05,{ }^{* *} p<.01,{ }^{* * *} \mathrm{p}<.001}$

Appendix B. The result of hierarchical multiple regression on a school rule

\begin{tabular}{|c|c|c|c|}
\hline Independent variable & $\begin{array}{c}\text { Model 1 } \\
\beta\end{array}$ & $\begin{array}{c}\text { Model } 2 \\
\text { B }\end{array}$ & $\begin{array}{c}\text { Model } 3 \\
\text { B }\end{array}$ \\
\hline \multicolumn{4}{|l|}{ Step 1} \\
\hline Ego-resiliency & $.369^{* * *}$ & $.198^{* * * *}$ & $.171^{* * * *}$ \\
\hline \multicolumn{4}{|l|}{ Step 2} \\
\hline \multicolumn{4}{|l|}{ Parenting style } \\
\hline Supervision & & $.241^{* * * *}$ & $.230^{* * *}$ \\
\hline Affection & & $.085^{* *}$ & .059 \\
\hline Rational explanation & & $.103^{* * * *}$ & $.090^{* *}$ \\
\hline Inconsistency & & $-.064^{*}$ & $-.069^{* *}$ \\
\hline Unreasonable expectation & & .034 & .027 \\
\hline Excessive interference & & -.056 & $-.063^{*}$ \\
\hline \multicolumn{4}{|l|}{ Step 3} \\
\hline \multicolumn{4}{|l|}{ Peer attachment } \\
\hline Communication & & & $.126^{* * * *}$ \\
\hline Trust & & & -.014 \\
\hline Alienation & & & .035 \\
\hline$\overline{\mathrm{R}^{2}}$ & .136 & .263 & .272 \\
\hline Adjusted $\mathrm{R}^{2}$ & .136 & .260 & .269 \\
\hline $\mathrm{F}$ & $315.726^{* * * *}$ & $101.576^{* * * *}$ & $74.446^{\text {***** }}$ \\
\hline$\Delta \mathrm{R}^{2}$ & & .127 & .009 \\
\hline$\Delta \mathrm{F}$ & & $94.713^{* * * *}$ & $32.145^{* * *}$ \\
\hline
\end{tabular}

$p<.05,{ }^{* *} p<.01,{ }^{* * *} \mathrm{p}<.001$ 
Appendix C. The result of hierarchical multiple regression on friendship

\begin{tabular}{|c|c|c|c|}
\hline Independent variable & $\begin{array}{c}\text { Model } 1 \\
\beta\end{array}$ & $\begin{array}{c}\text { Model } 2 \\
\text { B }\end{array}$ & $\begin{array}{c}\text { Model } 3 \\
\mathrm{~B}\end{array}$ \\
\hline \multicolumn{4}{|l|}{ Step 1} \\
\hline Ego-resiliency & $.520^{* * * *}$ & $.363^{* * * *}$ & $.253^{* * * *}$ \\
\hline \multicolumn{4}{|l|}{ Step 2} \\
\hline \multicolumn{4}{|l|}{ Parenting style } \\
\hline Supervision & & $.192^{* * *}$ & $.146^{* * *}$ \\
\hline Affection & & $.114^{* * * *}$ & .050 \\
\hline Rational explanation & & $.069^{* *}$ & $.057^{*}$ \\
\hline Inconsistency & & $-.096^{* * *}$ & $-.067^{* *}$ \\
\hline Unreasonable expectation & & .017 & .016 \\
\hline Excessive interference & & $-.114^{* * *}$ & $-.097^{* * *}$ \\
\hline \multicolumn{4}{|l|}{ Step 3} \\
\hline \multicolumn{4}{|l|}{ Peer attachment } \\
\hline Communication & & & $.121^{* * * *}$ \\
\hline Trust & & & $.196^{* * * *}$ \\
\hline Alienation & & & $-.083^{* * * *}$ \\
\hline $\mathrm{R}^{2}$ & .271 & .406 & .476 \\
\hline Adjusted R² & .270 & .404 & .474 \\
\hline $\mathrm{F}$ & $741.828^{* * *}$ & $194.562^{* * *}$ & $180.928^{* * * *}$ \\
\hline$\Delta \mathrm{R}^{2}$ & & .135 & .070 \\
\hline$\Delta \mathrm{F}$ & & $75.649^{* * *}$ & $88.989^{* * * *}$ \\
\hline
\end{tabular}

$* \mathrm{p}<.05, * * \mathrm{p}<.01, * * * \mathrm{p}<.001$

Appendix D. The result of hierarchical multiple regression on the teacher-student relationship

\begin{tabular}{|c|c|c|c|}
\hline Independent variable & $\begin{array}{c}\text { Model } 1 \\
\beta\end{array}$ & $\begin{array}{c}\text { Model } 2 \\
\beta\end{array}$ & $\begin{array}{c}\text { Model } 3 \\
\text { B }\end{array}$ \\
\hline \multicolumn{4}{|l|}{ Step 1} \\
\hline Ego-resiliency & $.408^{* * * *}$ & $.265^{* * *}$ & $.218^{* * * *}$ \\
\hline \multicolumn{4}{|l|}{ Step 2} \\
\hline \multicolumn{4}{|l|}{ Parenting style } \\
\hline Supervision & & $.093^{* * * *}$ & $.075^{* *}$ \\
\hline Affection & & $.159^{* * *}$ & $.121^{* * * *}$ \\
\hline Rational explanation & & $.096^{* * * *}$ & $.083^{* *}$ \\
\hline Inconsistency & & .024 & .020 \\
\hline Unreasonable expectation & & .047 & .038 \\
\hline Excessive interference & & -.045 & -.054 \\
\hline \multicolumn{4}{|l|}{ Step 3} \\
\hline \multicolumn{4}{|l|}{ Peer attachment } \\
\hline Communication & & & $.091^{* * *}$ \\
\hline Trust & & & $.080^{*}$ \\
\hline Alienation & & & .043 \\
\hline $\mathrm{R}^{2}$ & .166 & .237 & .254 \\
\hline Adjusted $\mathrm{R}^{2}$ & .166 & .234 & .250 \\
\hline $\mathrm{F}$ & $399.316^{* * * *}$ & $88.501^{\text {**** }}$ & $67.608^{* * *}$ \\
\hline$\Delta \mathrm{R}^{2}$ & & .071 & .016 \\
\hline$\Delta \mathrm{F}$ & & $30.755^{* * *}$ & $14.623^{* * *}$ \\
\hline
\end{tabular}

\section{Copyrights}

Copyright for this article is retained by the author(s), with first publication rights granted to the journal.

This is an open-access article distributed under the terms and conditions of the Creative Commons Attribution license which permits unrestricted use, distribution, and reproduction in any medium, provided the original work is properly cited. 